\title{
Vegetation Database of Québec (MRNF)
}

\author{
Jocelyn Gosselin \& Mélanie Major
}

\begin{abstract}
An ecological forest inventory was conducted from 1986 to 2000 in the portion of the Quebec province south of the 52nd parallel. The resulting database contains data from 28,425 ecological relevés located throughout the different bioclimatic domains of Quebec. For each relevé, information was gathered on both the vegetation composition and physical environment. Vegetation composition is described by several variables including tree species composition, floristic composition and species cover of different height strata for woody vascular plants as well as cover of herbaceous vascular plants, bryophytes and lichens. Variables describing the physical environment include altitude, slope inclination and aspect, microrelief, bedrock geology and surficial deposit, drainage, humus type, stoniness and soil texture. Data from these relevés form the basic structure underlying the hierarchal ecological classification system of the Ministère des Ressources naturelles et de la Faune (MRNF). The data was also used to develop ecological classification field guides specific to each of the province's ecological regions, providing detailed ecological knowledge to forest managers throughout the province. Finally, data from ecological relevés were used to develop Canadian National Vegetation Classifications (CNVC) vegetation associations. This report describes the available content in the Vegetation Database of Québec (MRNF) (GIVD ID NA-CA-002).
\end{abstract}

Keywords: ecological forest inventory; ecological relevé; physical environment; vegetation composition.

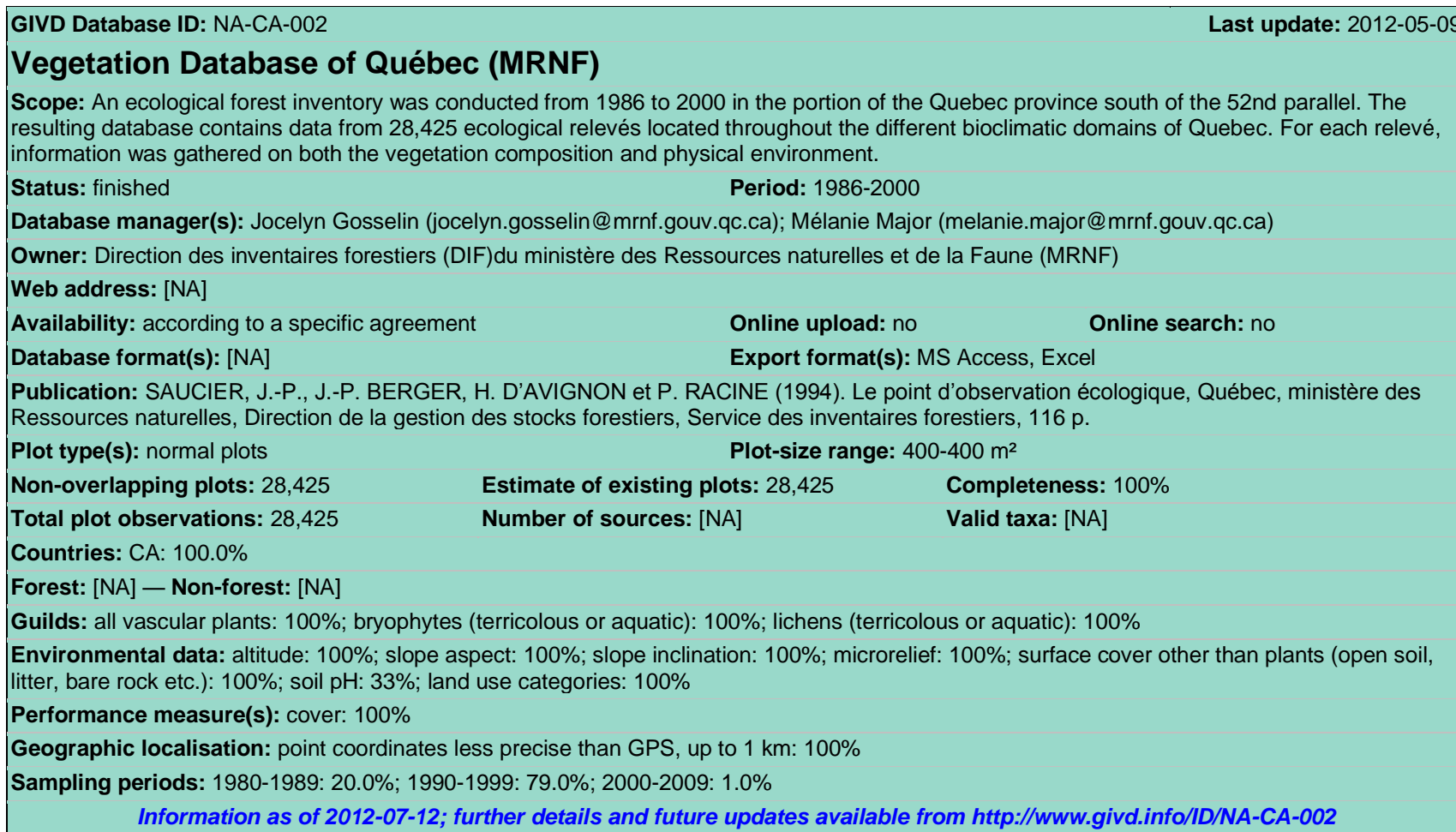

Jocelyn Gosselin (jocelyn.gosselin@mrnf.gouv.qc.ca), Mélanie Major* (melanie.major@mrnf.gouv.qc.ca) Direction des inventaires forestiers (DIF), Ministère des Ressources naturelles et de la Faune (MRNF), 880 chemin Ste-Foy, 5e étage, G1S 4X4 Québec, CANADA

*Corresponding author 